\title{
Slow-grown in vitro conservation of Heliconia champneiana cv. Splash under different light spectra
}

\author{
Paulo Hercílio Viegas Rodrigues ${ }^{1 *}$, Flávia Arruda ${ }^{1}$, Victor Augusto Forti ${ }^{2}$
}

${ }^{1}$ University of São Paulo/ESALQ - Dept. of Crop Science, C.P. $09-13418-900-$

Piracicaba, SP - Brazil.

2University Methodist of Piracicaba - Dept. of Biology, Rod. do Açúcar, km 156 - 13400-911 - Piracicaba, SP - Brazil.

*Corresponding author <phrviegas@usp.br>

Edited by: Leonardo Oliveira Medici

Received September 26, 2016

Accepted January 20, 2017

\begin{abstract}
In vitro techniques, with the purpose of conserving the genetic resources of plants, are fundamental to the feasibility of establishing germplasm banks and enabling the commercial production of micropropagated plants. The aim of this study was to evaluate the use of different spectra of light in in vitro germplasm conservation by slow grown storage of Heliconia Champneiana cv. Splash. Explants of heliconia in vitro were submitted to the following light treatments: CW (control white), B100 (100 \% blue), R100 (100\% red) and R70B30 (70 \% red/30 \% blue), all with $\mathrm{PFD}=25 \mu \mathrm{mol} \mathrm{m} \mathrm{s}^{-1}$, maintained in vitro for two time periods, namely P1, 6 weeks and P2, twelve weeks, and were statistically evaluated after each interval with respect to: height, fresh weight, number and length of roots, number of leaves, and pseudostem diameter, in addition to the rate of acclimatization in percentage terms. Treatment B100 presented the lowest level of development in the two periods, and $100 \%$ survival in acclimatization.

Keywords: tissue culture, micropropagation, ornamental plants
\end{abstract}

\section{Introduction}

Flower growing in Brazil has been increasing constantly over the last few years, according to the Brazilian Institute of Floriculture (IBRAFLOR, 2015). One of the segments of floriculture that especially attracts attention is tropical flowers, with Heliconias presenting outstanding characteristics, such as rusticity, beauty, and various colors in their bracts. The production of in vitro plants is fundamental to commercial cultivation and the cuttings used in tissue culture (Rodrigues et al., 2013).

In vitro maintenance of genetic material, whether for conservation or plant production, requires frequent changes in the cultivation media that may vary according to the objective of the laboratory. This operational routine demands an adequate structure, consumption of cultivation medium and above all, qualified labor, which accounts for the major part of the cost of the operation (Tavazza et al., 2015). Other operational difficulties particular to in vitro propagation are as follows: in vitro plants are ready to be removed from the laboratory, but the greenhouse is not available to receive the plants, either because it is full of unsold plants, or occupied by plants that had previously been sold and the customer is not ready to remove the plants from the greenhouse. These operational difficulties may generate financial losses for both the laboratory and customer (Watt et al., 2000).

"Slow grown storage" refers to the techniques capable of reducing the in vitro development of a plant to a minimum; this involves reducing plant metabolism by increasing the in vitro period of the explant, without changing the genetic uniformity (or pattern) and the quality of the micropropagated plant (Kamińska et al., 2016). In effective reduction in the metabolism of plants in vitro, the cultivation conditions such as temperature, light period, and light intensity may be changed, and so may the components of the cultivation medium (organic and inorganic nutrients, osmotic and growth regulators) during the period of incubation (Thakur et al., 2015; Carvalho et al., 2014; Kaur et al., 2012).

Light sources with different wavelengths from light emitting diodes (LED) have been widely used in in vitro propagation in different crops such as sugarcane, anthurium and blueberry, with the purpose of increasing production and improving the quality of the plants (Maluta et al., 2013; Martinez-Estrada et al., 2016; Hung et al., 2016). Such light sources may have an effect on in vitro development with significant changes in the arrangements of the thylakoids in the chloroplasts, which reduces the size of the plants, in emission and length of the roots, number of stomata in the leaves and chlorophyl content (Maluta et al., 2013; Vieira et al., 2015; Macedo et al., 2011).

Thus, the aim of this study was to evaluate the use of different spectra of light at the in vitro stage of root growth and elongation of Heliconia Champneiana cv. Splash in slow grown storage.

\section{Materials and Methods}

Plants of Heliconia Champneiana cv. Splash were at the stage of the sixth subculture in vitro, in glass flasks (10 $\mathrm{cm}$ long by $10 \mathrm{~cm}$ in diameter) containing $40 \mathrm{~mL}$ of semisolid MS (Murashige and Skoog, 1962) culture media, with the addition of MS vitamins; $30 \mathrm{~g} \mathrm{~L}^{-1}$ sucrose; $1.8 \mathrm{mg} \mathrm{L}^{-1}$ gellam gum and $3 \mathrm{mg} \mathrm{L}^{-1}$ BAP (benzilaminopurine), incubated at a temperature of $25^{\circ} \mathrm{C} \pm 2$, subject to light period conditions of $16 / 8 \mathrm{~h}$ (day/night) at $50 \mu \mathrm{mol} \mathrm{m}^{2} \mathrm{~s}^{-1}$ by using fluorescent lamps. Plants of the same size were selected and separated; the aerial parts were excised, so as to form structures $1.5 \mathrm{~cm}$ long by $0.5 \mathrm{~cm}$ in diameter, for a total of 120 explants.

The explants selected were transferred to PYREX test tubes ( $15 \mathrm{~cm}$ long by $2.5 \mathrm{~cm}$ in diameter) with Kimble polypropylene lids, $25 \mathrm{~mm}$ in diameter, each containing 7 
$\mathrm{mL}$ of semi-solid culture media $1 / 2 \mathrm{MS}$, with the addition of MS vitamins; $30 \mathrm{~g} \mathrm{~L}^{-1}$ sucrose; $1.8 \mathrm{mg} \mathrm{L}^{-1}$ gellam gum; $0.1 \mathrm{mg} \mathrm{L}^{-1}$ IBA (idolbutiric acid) for the induction of root growth and elongation; $\mathrm{pH}$ was adjusted to 5.8 before sterilization and incubation was at a temperature of $25^{\circ} \mathrm{C} \pm$ 2; under light conditions of $16 / 8 \mathrm{~h}$ (day/night) consisting of light treatments with a LED lighting system in the colors red LPEL-06R3-B (620-630 nm) and blue LPEL-06B3B (455-475 nm). Three combinations of LED treatments were evaluated: $100 \%$ blue (B100), $100 \%$ red (R100), $70 \%$ red $+30 \%$ blue (R70B30) and control white (CW). Spectra 380-780 nm, fluorescent lamps, with the photon flux density (PFD) adjusted to $25 \mu \mathrm{mols} \mathrm{m}^{2} \mathrm{~s}^{-1}$ were used in all the treatments, and measurements were taken using a Light Meter (LI-250A). Each treatment group consisted of thirty explants (totaling 120); the growth and development of the explants were evaluated over two time periods, without any subcultures developing. For each treatment, the test tubes were centralized and arranged equidistant to uniformly receive the spectrum evaluated. In the first time period (P1), after 6 weeks, fifteen plants were removed and washed in running water to remove the culture media, and the plant length was evaluated, based on the pseudostem up to the tip of the largest leaf $(\mathrm{mm})$; diameter of the pseudostem at $1.0 \mathrm{~cm}$ from the base $(\mathrm{mm})$; number of leaves; fresh weight of the plant $(\mathrm{g})$; number of roots and length of the largest root $(\mathrm{mm})$. In the second time period (P2), the remaining explants were maintained in the proposed treatments until a period of 12 weeks had passed, when they were submitted to the same evaluation procedures as those previously mentioned. The experimental design used was entirely randomized in the split-plot arrangement, with the plots being represented by the treatments, and the sub-plots by time. The data obtained were submitted to an analysis of variance in the split-plot arrangement, and the mean values were compared by Tukey test at a $5 \%$ level of significance (Statistical Analysis System) between the treatments proposed and between each time period evaluated. After the evaluations of each time period, the plants were acclimatized in 24-cell trays, using the commercial substrate "BASE Horticultura", and were maintained in the greenhouse with $80 \%$ shade (Aluminet) and relative humidity of $90 \%$ for seven days (Rodrigues et al., 2005), to evaluate the plant survival, expressed in percentage terms.

\section{Results and Discussion}

The characteristics measured in the trial, according to the Tukey test, were influenced by the use of the different light spectra. In the comparison, the characteristics evaluated showed a significant difference between treatments, except for the pseudostem diameter (Table 1). Specific wavelengths presented different effects when compared with CW, and these were repeated in the second time period evaluated. Blue light (B100) induced lower fresh mass, height of explants, number of roots/plant and root length, but induced a larger number of leaves/

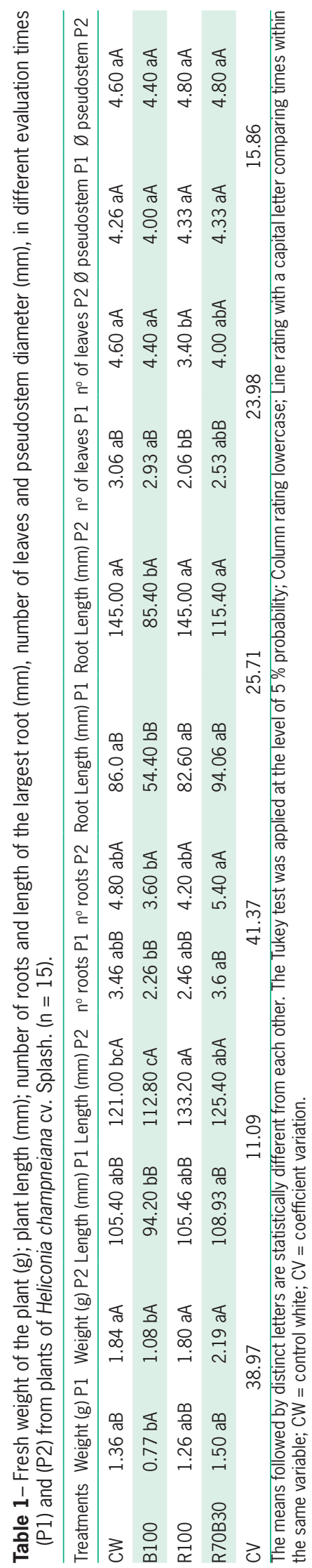


plant, together with CW. Red light (R100) induced a lower number of leaves/plant, while the combination of red/blue light (R70B30) induced higher fresh weight, height of explants and number of roots. The majority of characteristics measured in (P1) were repeated in (P2), except for root length which in P2 was exceeded by CW and R100 compared with the combination R70B30. In the comparison between the two time periods, no significant differences were found for the characteristic fresh mass in B100, which in P1 presented $0.77 \mathrm{~g}$ and $1.08 \mathrm{~g}$ in P2 (Table 1). In the remaining characteristics evaluated, there were significant differences between the time periods evaluated. The effects and applications of different spectra of light from LEDS on the in vitro cultivation of plants have been extensively reported by different authors in diverse cultures (Gupta and Jatothu, 2013). The results of the present study indicated that the use of blue light in in vitro conservation in minimum growth was promising and cast a new perspective on this area. Inhibition of plant development related to the use of blue light during the in vitro process, has been reported in crops such as potato (Luz et al., 2015), chrysanthemum (Kurilčik et al., 2008), blueberry (Hung et al., 2016) and grape (Poudel et al., 2008). In general, the blue component inhibited elongation of the plantlets and root formation in vitro. In an in vitro study on chrysanthemums, Kim et al. (2004) related that active phytochromes are related to the stimulus of in vitro development and increase in mass. The activation of phytochromes occured at the red and far red wavelengths existent in the CW, R100 and R70B30 treatments evaluated. On the other hand, the blue light, in which the red and far red wavelengths do not occur, did not activate the phytochromes sufficiently, as they did in B100 (Nhut et al., 2003).

The reduced gain in fresh mass between the time periods, associated with the induction of a lower number of roots, root length and lower height of the plants, found in B100, were visually evident after 12 weeks (Figure 1). In the CW, R100 and R70B30 treatments, the authors noted that the high density of the roots formed at the base of the plants, was shown to be greater than that in B100. In addition to the lower height of the plant induced in B100, the absence of yellowing of the leaves was also visually evident, a characteristic that was visible in the other treatments evaluated. The occurrence of yellowing leaves is frequently associated with stress caused by the in vitro environment resulting from the scarcity of nutrients in the culture medium and/or difficulties in gaseous exchanges, which accelerates the processes of senescence. These characteristics are commonly observed in plants that exceed the maximum time spent in vitro (Pimenta et al., 2013; Kevers et al., 2004).

The final quality of plant material kept in slow growth storage in vitro conservation must be the best possible, given the conditions to which explants are submitted to in vitro. On many occasions, the process of in vitro propagation may cause morphological, physiological and anatomical changes that make the ex vitro acclimatization stage difficult (Chandra et al., 2010). In the acclimatization

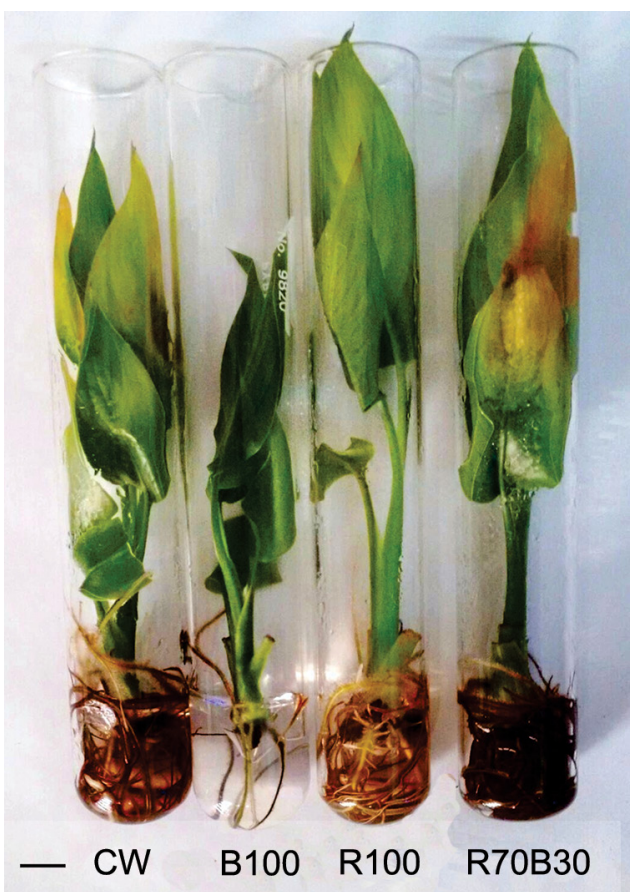

Figure 1 - Heliconia champneiana cv. Splash plants, after 12 weeks in vitro under treatments with different light quality. Barr: $10 \mathrm{~mm}$; $\mathrm{CW}=$ control white.

of Heliconia bihai cv. Lobster Claw, explants propagated in vitro, Rodrigues et al. (2005) reported greater efficiency in the process of acclimatization in a greenhouse with shade as beginning at $50 \%$, attaining a peak in efficiency of 80 $\%$. The results obtained in the acclimatization trial from all the plants of all the treatments evaluated were 100 $\%$ of the plants acclimatized in the conditions proposed in $\mathrm{P} 1$. The same did not occur in $\mathrm{P} 2$, in which survival percentages of $87 ; 100 ; 87$ and $73 \%$, were obtained for the CW, B100, R100 and R70B30 treatments, respectively. No effect of differentiated light treatments interfered in the acclimatization in $\mathrm{P} 1$, which could result in the loss of plants and consequent loss to the laboratory or to an in vitro conservation program. In $\mathrm{P} 2$, an advanced condition of senescence in the roots was observed in CW, R100 and in R70B30 this resulted in the loss of material during the acclimatization process. In B100, in spite of the reduced size, the plants were firm and without symptoms of senescence in the leaves and few roots emitted, which probably contributed to the better result in acclimatization after 12 weeks in vitro. In the surviving plants, no morphological changes such as leaf variegations or malformations of the leaf blade - common characteristics of possible somaclonal variants - were observed in any of the treatments after eight weeks of acclimatization. The authors' concern regarding this evaluation was justified, because a long period spent in in vitro conditions may favor the development of somaclonal variation (Bairu et al., 2011; Xin et al., 2015). 
The results of the present study indicated that blue light used in cultivation in vitro was efficient in maintaining the explants at reduced growth, and did not alter the quality of the plants, even after 12 weeks in vitro. In the case of the culture under study, the subcultures proceeded regularly every 21 days. From the data that were reported, the culture with reduced vegetative development was maintained for 84 days. For a commercial laboratory, this result represents savings in labor and culture medium due to the increase in subculture periods, and the increased ease of cleaning explants resulting from reduced root formation.

\section{Acknowledgements}

The authors thank to São Paulo State Foundation for Research Support - FAPESP (2015/14192-4) to financial support.

\section{References}

Bairu, M.W.; Aremu, A.O.; Van Staden, J. 2011. Somaclonal variation in plants: causes and detection methods. Plant Growth Regulation 63: 147-173.

Carvalho, V.; Santos, D.S.; Nievola, C.C. 2014. In vitro storage under slow growth and ex vitro acclimatization of the ornamental bromeliad Acanthostachys strobilacea. South African Journal of Botany 92: 39-43.

Chandra, S.; Bandopadhyay, R.; Kumar, V.; Chandra, R. 2010. Acclimatization of tissue cultured plantlets: from laboratory to land. Biotechnology Letters 32: 1199-1205.

Gupta, S.D.; Jatothu, B. 2013. Fundamentals and applications of light-emitting diodes (LEDs) in in vitro plant growth and morphogenesis. Plant Biotechnology Reports 7: 211-220.

Hung, C.D.; Hong, C.H.; Kim, S.K.; Lee, K.H.; Park, J.Y.; Nam, M.W.; Choi, D.H.; Lee, H.I. 2016. LED light for in vitro and ex vitro efficient growth of economically important highbush blueberry (Vaccinium corymbosum L.). Acta Physiologiae Plantarum 38: 152.

Instituto Brasileiro de Floricultura [IBRAFLOR]. 2015. Release press $=$ Release imprensa. Available at: http://www.ibraflor. com/publicacoes/vw.php?cod = 213 [Accessed June 16, 2015] (in Portuguese).

Kamińska, M.; Skrzypek, E.; Wilmowicz, E.; Tretyn, A.; Trejgell, A. 2016. Effect of light conditions and ABA on cold storage and post-storage propagation of Taraxacum pieninicum. Plant Cell, Tissue and Organ Culture 127: 25-34.

Kaur, D.; Ogra, R.K.; Bhattacharya, A.; Sood, A. 2012. Changes in sugar levels during slow growth of Dendrocalamus hamiltonii somatic embryos due to liquid paraffin overlay. In vitro Cellular \& Developmental Biology-Plant 48: 120-126.

Kevers, C.; Franck, T.; Strasser, R.J.; Dommes, J.; Gaspar, T. 2004. Hyperhydricity of micropropagated shoots: a typically stressinduced change of physiological state. Plant Cell, Tissue and Organ Culture 77: 181-191.

Kim, S.J.; Hahn, E.J.; Heo, J.W.; Paek, K.Y. 2004. Effects of LEDs on net photosynthetic rate, growth and leaf stomata of chrysanthemum plantlets in vitro. Scientia Horticulturae 101: 143-151.
Kurilčik, A.; Miklušytè-Canova, R.; Dapkūnienè, S.; Žilinskaitė, S.; Kurilčik, G.; Tamulaitis, G.; Žukauskas, A. 2008. In vitro culture of Chrysanthemum plantlets using light-emitting diodes. Central European Journal of Biology 3: 161-167.

Luz, T.C.L.A.; Cardoso, L.D.; Alves, R.B.N.; Matsumoto, K. 2015. Photomorphogenesis by LED lighting on potato and Brazilian ginseng for medium-term in vitro conservation. Acta Horticulturae 1083: 513-517.

Macedo, A.F.; Leal-Costa, M.V.; Tavares, E.S.; Lage, C.L.S.; Esquibel, M.A. 2011. The effect of light quality on leaf production and development of in vitro-cultured plants of Alternanthera brasiliana Kuntze. Environmental and Experimental Botany 70: 43-50.

Maluta, F.A.; Bordignon, S.R.; Rossi, M.L.; Ambrosano, G.M.B.; Rodrigues, P.H.V. 2013. In vitro culture of sugar cane under different light sources. Pesquisa Agropecuária Brasileira 48: 1303-1307 (in Portuguese, with abstract in English).

Martinez-Estrada, E.; Caamal-Velazquez, J.H.; Morales-Ramos, V.; Bello-Bello, J.J. 2016. Light emitting diodes improve in vitro shoot multiplication and growth of Anthurium andreanum Lind. Propagation of Ornamental Plants 16: 3-8.

Murashige, T.; Skoog, F. 1962. A revised medium for rapid growth and bio assays with tobacco tissue cultures. Physiologia Plantarum 15: 473-497.

Nhut, D.T.; Takamura, T.; Watanabe, H.; Okamoto, K.; Tanaka, M. 2003. Responses of strawberry plantlets cultured in vitro under superbright red and blue light-emitting diodes (LEDs). Plant Cell, Tissue and Organ Culture 73: 43-52.

Pimenta, M.R.; Ribeiro, C.; Soares, C.Q.G.; Mendes, G.C.; Braga, V.F.; Reis, L.B.; Otoni, W.C.; Resende, C.F.; Viccini, L.F.; Peixoto, P.H.P. 2013. Ethylene synthesis inhibition effects on oxidative stress and in vitro conservation of Lippia filifolia (Verbenaceae). Brazilian Journal of Biology 73: 617-621.

Poudel, P.R.; Kataoka, I.; Mochioka, R. 2008. Effect of red-and bluelight-emitting diodes on growth and morphogenesis of grapes. Plant Cell, Tissue and Organ Culture 92: 147-153.

Rodrigues, P.H.V.; Lima, A.M.L.P.; Ambrosano, G.M.B.; Dutra, M.D.F.B. 2005. Acclimatization of micropropagated Heliconia bihai (Heliconiaceae) plants. Scientia Agricola 62: 299-301.

Rodrigues, P.H.V.; Gato, A.M.G.; Pereira, J.O. 2013. In vitro establishment of heliconia from floral apex. Acta Horticulturae 1000: 553-558

Tavazza, R.; Rey, A.N.; Papacchioli, V.; Pagnotta, M.A. 2015. A validated slow-growth in vitro conservation protocol for globe artichoke germplasm: a cost-effective tool to preserve from wild to elite genotypes. Scientia Horticulturae 197: 135-143.

Thakur, S.; Tiwari, K.L.; Jadhav, S.K. 2015. In vitro approaches for conservation of Asparagus racemosus Willd. In vitro Cellular \& Developmental Biology-Plant 51: 619-625.

Vieira, L.D.; Fraga, H.P.D.; Anjos, K.G.; Puttkammer, C.C.; Scherer, R.F.; Silva, D.A.; Guerra, M.P. 2015. Light-emitting diodes (LED) increase the stomata formation and chlorophyll content in Musa acuminata (AAA) 'Nanicao Corupa' in vitro plantlets. Theoretical and Experimental Plant Physiology 27: 91-98.

Watt, M.P.; Thokoane, N.L.; Mycock, D.; Blakeway, F. 2000. In vitro storage of Eucalyptus grandis germplasm under minimal growth conditions. Plant Cell, Tissue and Organ Culture 61: 161-164.

Xin, P.; Qingyong, J.; Hao, W.; Yulan, L. 2015. Slow-growth conservation and clonal fidelity of Tetrastigma hemsleyanum microplants. In Vitro Cellular \& Developmental Biology Plant 51: 463-470. 